\title{
The Motivations Behind Child Welfare Work
}

\section{Samuel J. Dickman, School of Social Work, Indiana University - Bloomington}

Faculty Mentor: Dr. Carol Hostetter

\section{ABSTRACT}

This report seeks to explore the findings of a qualitative research study concerning the motivations behind child welfare work. Child welfare is a major field within the social work profession that demands a great deal of expertise and effort from workers. Professionals employed as case managers within the child welfare field are held accountable for a wide variety of social work roles, often placing these individuals at risk of emotional trauma and high levels of work-related stress. Due to this, workers who remain in the field for extensive periods of time often experience strong sensations of purpose relative to their work. Our study found that child welfare caseworkers were motivated by altruism and a deep desire to improve the lives of their clients. They were also kept motivated by the successes that came from time to time. While trials seem to be experienced on a regular basis, child welfare caseworkers generally found their work to be a positive presence within the families they serve. Further research is needed to expound upon the findings of this study.

KEYWORDS: child welfare, motivation, altruism, case manager, secondary trauma

\section{INTRODUCTION}

$\mathrm{C}$ hild welfare work is a uniquely sensitive area of the social work profession. Families who come into a state's child welfare system often present a variety of underlying needs and are accompanied by complex layers of trauma. Workers in this field are held to a high standard of professionalism and are often entrusted with life-and-death responsibility. Prior to conducting this study, we hypothesized that individuals attracted to child welfare work are often motivated by deeply-held altruistic beliefs; to continue to serve clients with the sort of passion and dedication that speaks to the core of quality client engagement, it is imperative that workers remember their original sources of motivation.

The discipline of social work is widely seen as one that is best suited to educating and training child welfare workers (Folaron \& Hostetter, 2006). Therefore, social work educators are particularly interested in understanding who is drawn to child welfare work. Understanding the motivation of child welfare workers also helps recruit and retain excellent people for the field.

This study seeks to offer an explanation as to what motivates contemporary child welfare workers. By inviting participants to share their experiences of both arriving to and remaining in the field, they may be reminded of the personal reasons with which they began this chapter of their careers. In turn, all social workers and other professionals with an interest in the child welfare field will have the opportunity to expand their understanding of the realities current child welfare workers face.

\section{BACKGROUND}

Child welfare workers have garnered an increased amount of interest in recent years. Policy reformations across the county have made an effort to recruit, train, and keep quality workers who can perform to a new standard of care. While obtaining statistics from server databases and surveys is a feasible task, solid qualitative data is difficult to collect due to the overscheduled and busy nature of child welfare workers.

Barth, Lloyd, Christ, Chapman, \& Dickinson (2008) provided the field with a variety of in-depth, contemporary, and reasonably-generalizable data about the characteristics of child welfare workers. The researchers took multiple factors into account. In addition to worker satisfaction, home life, and income, the backgrounds and training of workers were analyzed as well. By utilizing data gathered from 92 clustered primary sampling units, the researchers were able to collect regionally-sensitive data from across the United States. Job satisfaction, urban status, gender, race, experience, supervision, social work degrees, roles of the worker, and income were each assessed in detail.

Barth et al. (2008) found the child welfare field to be lacking in worker diversity. Case managers are still overwhelmingly female and white. Additionally, a case was made for demographic stability as this trend does not appear to be significantly different amongst recently-hired workers. Quality supervision was found to be the strongest predictor of satisfaction among child welfare workers, making an argument for the importance of strong and thorough advising and emotional support. Social workers were found to remain in the field the longest and to earn more money on average than their non-social work colleagues.

Jayaratne, Chess, and Kunkel (1986) utilized surveys to gather information from 75 female workers and their male spouses. Due to the demographic context of the state the researchers were analyzing, only 14 male-and-married workers were present, thus prompting the researchers to restrict their inquiries to female workers. Burnout, anxiety, depression, irritability, self-esteem, physical health, emotional support, and job satisfaction were assessed by the survey.

Jayaratne et al. (1986) concluded that female workers experiencing high levels of work-related anxiety and stress felt compelled to conceal their struggles. Workers lacking in access to or the knowledge of good support systems and supervision were the most likely to suffer from burnout and other risk factors. The researchers found a vicious cycle of job-related issues affecting marital satisfaction, resulting in 
marital conflicts negatively impacting job satisfaction.

The Social Work Policy Institute (2011) found supervision to be a key element in both the success and retention of workers. A variety of high expectations are placed upon supervisors, such as culturally-competent practice, the transmission of evidence-based practices, and addressing staff retention. However, fulfilling all of these roles simultaneously in realworld practice appears to be difficult and perhaps unfeasible. Therefore, if a supervisor is unable to fulfill these roles, the case managers beneath them will likely struggle to deliver quality services and ultimately remain in the field.

Unfortunately, the literature concerning the motivations behind child welfare work cannot be deemed extensive or exhaustive. The realities workers are experiencing will likely continue to receive more attention as an increasing emphasis is placed upon methods to recruit and keep workers. To reiterate the goal of this study, there is a need for an increased awareness as to why workers are both drawn to and remain within the child welfare field. In doing so, outside workers may be inspired to investigate a career in child welfare, while more awareness may be raised concerning the realities contemporary workers are facing. Agencies also may use the information to reach out to new workers and help retain ongoing workers. Perhaps most importantly, current workers may be encouraged to reflect upon the deeper reasons for which they entered the field.

\section{METHODS}

\section{Participants}

The present study used a convenience sample of child welfare workers $(N=6)$. To be eligible for participation, workers had to be currently employed as a case manager for their state's respective child welfare department. Study participants were not offered incentives for participating. The research was approved by the university's Institutional Review Board. Participants' gender is not disclosed so as to further protect their anonymity.

All workers who agreed to participate in this study were interviewed. Participants represent work on both the assessment and ongoing phases of child welfare case management. All individuals invited to participate were employed as Family Case Managers within a central region in the state of Indiana.

\section{Measures}

The instrument used to collect data for the present study was a seven-point questionnaire. This questionnaire was used by the researcher to interview study participants. The questionnaire was designed with the specific intention of protecting both worker and client confidentiality.

\section{Procedures}

Participants were interviewed by the researcher via the use of the instrument. Following an invitation to participate in the study, consenting participants scheduled a time to speak with the researcher that would be most convenient for the participant's schedule. Participants were offered the opportunity to participate through either a phone or face-to- face interview.

While conducting the interviews, the researcher reaffirmed the importance of confidentiality and asked participants to state whether or not they felt comfortable speaking in confidence in their current situation. Interviews began after each participant had given verbal consent. Participants were free to stop the interview at any point during the process.

\section{RESULTS}

1) How did you first come to learn of the child welfare field?

Participants' responses primarily centered on having some sort of prior contact with a child welfare worker. Some participants came to learn of the field via personal experiences as a child, while others came to know of child welfare work due to the issues experienced by their adult siblings. Participants also learned of case management opportunities in child welfare through engagement with other professions in a previous job setting. Workers may have been service providers or played a different role in the system, leading them to either be intrigued by or recommended to the child welfare field. One participant stated: "I was a service provider prior to coming to the state. I didn't know much about [the agency]. I purposefully went after my bachelor's so I could be a family case manager with [the agency]."

2) Was there a specific moment that caused you to feel "drawn" to the child welfare field? If not, was there some culmination of moments or experiences?

Participants mainly focused on their experiences as new workers in the child welfare field. A challenging moment during training, the first engagement with a family, or the first successful closure of a case seemed to give the participants inspiration to reaffirm their decision to work in child welfare. The participants described moments of clarity that validated the time, effort, and emotion they had invested in the job. Childhood experiences were also named as a compelling force to enter the child welfare field. Stated one participant: "Since I was a kid I've been interested in social work, although of course I didn't know what it was called back then. My dad is a drug addict, and so there were a lot of experiences and traumas that drew me to the field. My mom was a victim of domestic violence, so that's how I made it here." Participants seemed inspired to take action due to their personal experiences with neglect and abuse.

\section{3) What has been your proudest moment as a Family Case Manager?}

Participants exhibited two main sets of responses to this question. Some participants spoke of cherishing small victories, as they are often the only visible changes workers can witness in the field. This seemed to be especially the case for assessment-oriented workers, as they are only with families for a brief window of time as they determine whether the families need to be involved with the agency or not. One assessment worker described this, saying: "Celebrating the 
small stuff; seeing growth and small changes within parents, kids making improvements. Since I'm at the assessment phase I unfortunately don't get to see a lot of the happy endings; so holding onto the small things."

On the other hand, participants also shared stories of proud moments where they were able to witness a family truly overcoming their various challenges and issues. One participant stated: "When I did my first removal, the mom had hit rock-bottom; she was heavily addicted, very sick, and her life was falling apart. Little by little, I watched her put her life back together. The day the court reunified that family was one of the best days of my life." Participants were honored to play a role in these individuals' triumphs and at times were sincerely thanked by their clients. Still other participants were proud to have a sense of "saving" a child or adult family member from an abusive situation. Instances of domestic violence and sexual abuse were described as being particularly difficult to overcome, with witnesses and survivors often being very hesitant to reveal any information concerning their abuser. In these instances, participants were particularly proud of situations where they were able to help an individual or family "escape" an abuser.

\section{4) What has been your most trying experience as a Family Case Manager?}

Participants named a number of frustrations centering on a lack of time, resources, and client motivation. Several stated they felt the demands of the job, including extensive paperwork, constant yet brief meetings with clients, and massive caseloads, were seemingly impossible to meet within the standard timeframes governed by respective department policies. This was a major source of frustration for several participants, as they felt their potential impact for change within families was diminished by these administrative tasks.

One participant went into great detail about the struggle to balance their home and professional lives. "The most trying part of child welfare would be the secondary trauma and the burnout. There's no ability to turn it off. Even the individuals with the best boundaries still have trouble turning it off. When you're at home on the weekends or on vacation, the phone always rings, and I feel guilty about turning my phone off. If you have a worker that isn't wondering if someone might need something, I feel like I would be questioning why they aren't doing those things." This participant hinted at the guilt workers may face if they take time off, even for the brief period of one afternoon. Additionally, workers often struggle to process the sort of difficult life experiences their clients are going through. In turn, workers may begin to assume the burdens their clients face as their own.

Concerning client engagement, participants described the challenge of working with unmotivated clients. A child welfare department's involvement in a family's life is always time-limited, and for true client buy-in to take place the individuals must be open to making major life changes. Workers seemed to feel guilty for times they were unable to properly engage with a family as there are a variety of drastic consequences that may result. Participants stated the department may be pushed at times to either pursue a termination of parental rights or to list abuse or neglect as unsubstantiated, thus choosing between the "lesser of two evils." Workers often seem to be rushed by department policies to make concrete decisions on very limited information.

Participants also voiced serious challenges relating to secondary trauma and burnout. They seemed to be greatly distressed by serious instances they had witnessed while on the job, particularly in relation to child fatalities. One participant detailed his/her experiences with child fatalities: "The child had been left in a car and had passed; it was difficult because when I arrived the parents were still trying to process that their child was deceased, let alone handling the agency's involvement. There was another fatality that was a child that I had worked with previously; this one is difficult because I knew her when she was alive. They were difficult for different reasons; seeing the death of a three-year-old that was close to the age of my own child, versus the death of a child I had known before. It was so important for me to draw upon the support of my office family." Participants described how they processed events differently based upon their relation to the situation; meaning, whether or not they had a child at home of a similar age, had known the deceased child through a previous work-related relationship, and other personal reasons.

\section{5) Keeping proper observation of professional confidentiality} in mind, what family provided you with the most growth as a worker?

Participants were quick to point to a family that was either very challenging or particularly inspiring to work with. They described situations where a parent had reached a very low point in life, held fast by addictions or other issues, only to later rise above their life challenges and be reunited with their families. One participant described how they were inspired to take initiative: "There was a sex abuse case with three young girls, and I think it really opened my eyes to a lot of things. The things I took the liberty to learn on my own far surmounted anything I had done up to that point. I think it's important to understand what our families are going through. Sometimes I ask myself why- why would anyone do that? I think you have to dig deeper." This participant calls our attention to the need for continuous growth and increases in competency within workers.

Some participants also described families that were particularly challenging to engage in the case process. The workers attempted a variety of different intervention and interviewing strategies, but still struggled to connect with the individuals. In the end, the participants had to come to terms with the reality of these clients' situations and how they likely would struggle to cooperate with services from any worker. 
6) How has your view of child welfare work changed over time?

Some participants were hesitant to provide a detailed response to this question, citing their feeling of having only worked a brief time within the field as the primary reason.

Other participants spoke candidly about both the positives and negatives of how their time within the child welfare field has impacted their view of the profession. Some participants felt the work had hardened them; whereas they initially were very sympathetic toward the parents they worked with, they now found themselves expecting more accountability from clients. This was explained by one participant as "I have hardened, and now have a less emotional reaction; I'm more empathic with the children but have a higher expectation of parents. I used to really feel bad for the parents, but now I see that they have played a big role in the situation; they need to take responsibility and really prove their ability to improve to me."

Some participants spoke of their frustrations concerning child welfare work's failure to meet their original expectations. One participant stated: "Prior to starting with [the agency] it was all rainbows and butterflies; everything was going to be wonderful, their goal is to provide permanency and safety and wellbeing for children, it's great." They went on to say: "Our cases have become numbers on a to-do list. They're not humans anymore, they're not people; they don't have real needs and real strengths because there's not time to spend with them to treat them the way they need to be treated to actually see the successes. And I would say that 100 percent of the families that succeed are doing so because they want to succeed - not because we're doing something positive for them." The participants hoped to be spending a great deal of time working one-on-one with families and playing a major role in their progress, but instead they found themselves spending most of their energy meeting requirements, completing reports, and struggling to handle their over-sized caseloads.

Nevertheless, there was a pervasive optimism present when the participants spoke of the field. Participants continue to believe they are making some sort of positive impact upon the lives of their clients. Despite concerns with the department's general structure, participants are hopeful regarding the opportunity to help children and families.

7) What aspect or aspects of child welfare work give you the greatest sensations of purpose?

Participants were virtually unanimous in their appreciation of the opportunity to play a part in the improvement of a family's well-being. Workers seem to be touched deeply by witnessing their clients' triumph over the barriers in their lives, namely in overcoming whatever obstacles they may have been facing and eventually being reunified with their families. One participant described a couple of his/her most inspiring engagements: "One of my cases that I've had during my entire time with [the agency] we filed for termination, and I really had to fight for her. When I looked at the mother
I saw a young version of myself, and I always made sure to let her know that I believed in her and I believed that she could do it. We made it to reunification for trial home visit, and that was a very profound moment for me. My purpose was to see that happen- to never quit, never give up, never lose hope. I had a little gal tell me when I was a service provider that I was the first person to ever say they believed in her; and I think that's really important, because a lot of the families we work with have low self-esteem, and much of their involvement is generational and it's all they've ever known. To have someone from the outside tell them they can do it and they believe in them is so important." Participants stated that although they often struggle with the more difficult aspects of child welfare work, focusing on positive moments is key to remaining driven and invested in the work. Participants seemed to imply that a purpose-driven worker will find the most success in child welfare work.

\section{DISCUSSION}

\section{Motivations and Barriers}

After gathering and analyzing each participant's responses, it is reasonable to suggest that child welfare workers are fueled by primarily altruistic motivations. This altruism seems to be rooted in a desire to be a part of actionable change efforts to improve the lives of children and families. Workers may be inspired by the opportunity to play a significant role in improving the wellbeing of children and families. Participants were also motivated by their childhood experiences, with some having endured trauma from a young age; still others had been moved by the positive influence a caring adult had been in their young lives, seeming to encourage them to pursue a reprisal of that role for other children.

On the other hand, participants also seemed to be experiencing a great deal of pressure from their work environments. Participants repeatedly voiced concerns relative to the lack of available time they have to spend with families. Weighed-down by large caseloads and expected to complete subsequent paperwork in a timely fashion, participants seemed to feel limited.

\section{Institutional Constraints}

In addition to responding to the researcher's questioning concerning their motivations, some participants offered explanations of their struggles with the climate of their respective agencies. Participants seemed to be stressed by administrative duties, such as completing paperwork and meeting requirements while following a strict time table. Workers also voiced difficulties concerning the implementation of quality client engagement in the context of contemporary policies. Responses regarding policy could be interpreted to be the workers feeling more obligated to serve by policy than by the actual needs exhibited by their clients. Workers may feel pressured to perform "by the numbers" and potentially jeopardize client successes. 
Implications and Applications to Social Work Practice

Child welfare workers must perform a variety of social work roles, and participant responses seem to highlight some of the pressures that can come from juggling a variety of roles. The risks of secondary trauma and burnout appear to have serious implications, as some participants planned to soon leave their area of the child welfare field due to the severity of these stressors. Child welfare is known as a field with particularly high burn-out and lack of retention (Sprang, Craig, \& Clark, 2011). Participants felt their ability to implement social work roles was restricted by the policies and administrative requirements of their respective agencies. Based upon the responses of these participants, one could argue for a need to assess possible options for decreasing the time workers spend on administrative tasks with the goal of increasing client engagement. Such an exploration could increase the amount and quality of social work practice within the child welfare field while also speaking to the motivations present within the participants of this study.

\section{Limitations of the Research}

Although participants were able to offer in-depth responses to the questionnaire, this study is limited in generalizability. Due to the low amount of responses, this study cannot be used to speak for a broad range of workers. Additionally, participants primarily identified as female and white, limiting this study's potential application to those of other backgrounds.

\section{Future Research}

Future research on the motivations behind child welfare work could provide more breadth, depth, and support to the findings of this study. Further qualitative research with more participants could allow researchers to better-assess commonalities and recurring themes; additionally, since this study only included workers employed by the state of Indiana, future research could expand to other states and child welfare systems. Future research on this subject should also make a conscious effort to include participants of diverse backgrounds so as to take their unique experiences into account.

\section{APPENDIX A}

Research Instrument For Interviews on the Motivations behind Child Welfare Work

1. How did you first come to learn of the child welfare field?

2. Was there a specific moment that caused you to feel "drawn" to the child welfare field? If not, was there some culmination of moments or experiences?

3. What has been your proudest moment as a Family Case Manager?

4. What has been your most trying experience as a Family Case Manager?

5. Keeping proper observation of professional confidentiality in mind, what family provided you with the most growth as a worker?

6. How has your view of child welfare work changed over time?

7. What aspect or aspects of child welfare work give you the greatest sensations of purpose?

\section{AUTHOR INFORMATION}

All correspondence should be sent to sjdickma@indiana. edu. Alternatively, correspondence may be sent to Dr. Carol Hostetter at the Indiana University School of Social Work: 1127 East Atwater Avenue, Bloomington, IN 47401.

\section{ACKNOWLEDGMENTS}

I would like to acknowledge Dr. Carol Hostetter for her mentoring, support, and inspiration. I believe this eyeopening opportunity will serve as a continual source of encouragement as I begin my career. Additionally, to all child welfare workers - thank you for your compassion, your service, and your sacrifice.

\section{REFERENCES}

Barth, R. P., Lloyd, E. C., Christ, S. L., Chapman, M. V., \& Dickinson, N. S. (2008). Child welfare worker characteristics and job satisfaction: A national survey. Social Work, 53(3), 199-209.

Folaron, G., \& Hostetter, C. (2006). Is social work the best educational degree for child welfare practitioners? Journal of Public Child Welfare, 1(1), 65-83.

Jayaratne, S., Chess, W. A., \& Kunkel, D. A. (1986). Burnout: Its impact on child welfare workers and their spouses. Social Work, 31(1) , 53-59.

Social Work Policy Institute. (2011). Supervision: The safety net for front-line child welfare practice. Washington, DC: National Association of Social Workers.

Sprang, G., Craig, C., \& Clark, J. (2011). Secondary traumatic stress and burnout in child welfare workers: A comparative analysis of occupational distress across professional groups. Child Welfare, 90(6), 149-188. 
